Sharif University of Technology
Scientia Iranica
SCIENTIA
I RAN ICA
http://scientiairanica.sharif.edu

\title{
Strengthening and shape modification of fire-damaged concrete with expansive cement concrete and CFRP wrap
}

\author{
M. Hosseinpour ${ }^{a}$, M. Celikag ${ }^{a}$, and H. Akbarzadeh Bengar ${ }^{b, *}$ \\ a. Department of Civil Engineering, Faculty of Engineering, Eastern Mediterranean University, Famagust, North Cyprus, via \\ Mersin 10 Turkey. \\ b. Department of Civil Engineering, University of Mazandaran, Babolsar, Iran.
}

Received 18 March 2017; received in revised form 26 June 2017; accepted 13 November 2017

\section{KEYWORDS \\ Fire damaged \\ concrete; \\ Square specimens; \\ Strengthening; \\ Shape modification; \\ CFRP wrapping.}

\begin{abstract}
This paper reports the results of an experimental study that involved the investigation of the axial capacity of fire-damaged specimens repaired by expansive cement concrete and CFRP wrap. Specimens were subjected to axial compressive loading and their resulting stress-strain curves were recorded. Since the flat sides of the square samples remained unconfined, the cross-sections of the tested specimens largely remained unconfined. The FRP jacket was effective only along the two diagonals of the cross-section. Confinement is generally more effective in specimens with circular cross-sections than in those with square ones. The change in cross-section for some of the specimens from square to circular ones was implemented. To modify the shape, expansive cement concrete was utilized to fill the gap between the circular and square cross-sections. The test results indicated that heating up to $500^{\circ} \mathrm{C}$ caused a severe decline in compressive strength and the elastic modulus of concrete. Two layers of CFRP wrap around the concrete not only compensated the drop in compressive strength, but also increased the strength beyond that of unheated specimen. However, the effect of wrapping alone on the stiffness and the elastic modulus is negligible. The heated square specimens that were first subjected to shape modification and, then, wrapped by CFRP sheet experienced an increase in the strength and the elastic modulus. Therefore, the stiffness and the compression strength of fire-damaged square concrete specimens could be compensated fully by the use of shape modification and CFRP wrapping of the cross-section.

(C) 2019 Sharif University of Technology. All rights reserved.
\end{abstract}

\section{Introduction}

Concrete structures show good performance during fire owing to the low thermal conductivity of concrete. Based on past experience of real fire-damaged cases,

*. Corresponding author. Tel.: +98323300104 E-mail addresses: mehdi.hosseinpour@cc.emu.edu.tr (M. Hosseinpour); murude.celikag@emu.edu.tr (M. Celikag); h.akbarzadeh@umz.ac.ir (H. Akbarzadeh Bengar).

doi: $10.24200 /$ sci. 2017.4592 it is rare for a reinforced concrete building to collapse due to fire, and concrete structures severely damaged by fire can be repaired successfully [1].

Once a Reinforced Concrete (RC) structure becomes heated up, changes in some mechanical properties and the deformation caused by heating would lead to a reduction in compressive strength of the concrete and a change in stress-strain response during both heating and cooling time. The residual strength of $\mathrm{RC}$ structures after being exposed to fire is somewhat lower than their capacity before heating, even if the damage is not visible $[2,3]$. These changes will bring 
about a breakdown in concrete structure, affecting its mechanical properties. Therefore, the strength of concrete members without any visible damage may reduce due to elevated temperatures. The decision on repairing or demolishing of a structure should be made according to economic considerations, such as direct costs and time.

Compressive strength of concrete at an elevated temperature is of primary interest in a fire-resistant design. Compressive strength of concrete at ambient temperature depends on water-cement ratio, aggregatepaste interface transition zone, curing conditions, type and size of aggregate, type of admixture, and type of stress [4]. At high temperature, compressive strength is highly influenced by room temperature strength, rate of heating, and binders in batch mix (such as silica fume, fly ash, and slag). Over the years, numerous studies have examined the effect of high temperature on mechanical properties and compressive strength of concrete [5-11].

In previous studies, various kinds of materials for external covering of concrete, such as Shape Memory Alloy (SMA) wires $[12,13]$, steel wrapping plates [14], and Carbon Fiber Reinforced Polymer (CFRP) sheets [15-19], were used to increase the strength. The use of CFRP wrap for strengthening RC has been widely used, and there has been a growing number of studies for evaluating the fire performance of such applications [20,21].

Repairing and strengthening of the RC structures have become more common in the past decade due to increased knowledge and confidence about the use of CFRP. There are many researches on retrofitting design with CFRP to increase the load capacity of concrete members at ambient temperature [18-27].

One of the simple and fast methods for repairing reinforced concrete columns is the use of CFRP wrapping. In recent years, CFRP wrap has been used by prominent researchers for repairing, reinforcing, and strengthening of concrete column [28-31]. However, until now, only few studies on the reinforced concrete structures damaged by fire and application of CFRP for their repair have been carried out [32-36].

According to Karbhari and Gao, externally bonded CFRP composite jackets could have a significant effect on the confinement of the concrete columns with circular sections [37]. The study carried out by Rochette and Labossiére indicated that CFRP confinement was relatively less effective in increasing the compressive strength of columns with square and rectangular sections as opposed to those with circular sections [38]. The square and rectangular columns largely remained unconfined, and the CFRP jackets were only effective along the two diagonals of the crosssection. The presence of internal bars could limit the ability of rounding the corners of square and rectangu- lar columns. The lack of confinement in these columns affected the softening behavior and caused premature rupture in CFRP; therefore, the potential capacity of CFRP was not used [39]. One possible method for improving the effect of CFPR jackets on square and rectangular columns is to modify the shape of the cross-section into an elliptical, oval, or circular section $[39,40]$; in this respect, experiments indicate that the elliptical sections provide supreme performance, compared to confined rectangular columns. It should be mentioned that one way to do this improvement is the use of non-shrinkable cement concrete in the annular gap space. Then, the formworks of nonshrinkable concrete are removed, and the section is wrapped with CFRP jackets. There are few studies in the literature on the use of an expansive factor in the gap between column and CFRP jacket to reach active confinement [40-42].

Nevertheless, there are no specimens in the literature whose shape of a fire-damaged concrete sample has been modified using an expansive agent and actively confined with CFRP shells.

\section{Experimental program}

The main goal of the experimental part of this study is to investigate the effect of CFRP wrapping and the shape modification on the repair of fire-damaged concrete specimens. All specimens at the time of construction had the same cross-sectional size; prismatic sections were of $100 \mathrm{~mm} \times 100 \mathrm{~mm}$, and the ones with circular cross-sections had a diameter of $150 \mathrm{~mm}$. The height of all specimens was considered as $300 \mathrm{~mm}$. The specimens were tested under the following five conditions:

1. Un-heated specimens;

2. Post-heated specimens without any spalling due to heating;

3. Post-heated specimens without any spalling due to heating and wrapped with Carbon FiberReinforced Polymer (CFRP) jacket after heating;

4. Post-heated specimens repaired and shape modified with expansive cement concrete;

5. Post-heated specimens repaired with both expansive cement concrete and CFRP.

The modeled specimens were given unique names. These names are composed of three parts. The first part indicates whether the specimen is un-heated $(\mathrm{U})$ or post-heated $(\mathrm{P})$. The second part corresponds to the cross-section and shape modification. The square specimens without shape modification (S), the circular specimens without shape modification $(\mathrm{C})$, and the shape-modified specimens (M) are presented. Furthermore, the third part represents the strengthening with 
Table 1. Details of tested specimens.

\begin{tabular}{|c|c|c|c|c|c|c|}
\hline \multirow{2}{*}{$\begin{array}{l}\text { Specimen } \\
\text { ID }\end{array}$} & \multicolumn{2}{|c|}{$\begin{array}{c}\text { Original cross-section } \\
(\mathrm{mm})\end{array}$} & \multirow{2}{*}{$\begin{array}{c}\text { Modified } \\
\text { cross-section }(\mathbf{m m}) \\
(\text { circular })(\mathbf{d})\end{array}$} & \multirow{2}{*}{$\begin{array}{c}\text { Area } \\
\text { increase (\%) }\end{array}$} & \multirow[b]{2}{*}{ Heating } & \multirow[b]{2}{*}{ Wrapping } \\
\hline & Circular (d)* & Square $(\mathbf{a})^{* *}$ & & & & \\
\hline U-S-O & - & 100 & - & - & - & - \\
\hline P-S-O & - & 100 & - & - & $\sqrt{ }$ & - \\
\hline U-S-WR & - & 100 & - & - & - & $\sqrt{ }$ \\
\hline P-S-WR & - & 100 & - & - & $\sqrt{ }$ & $\sqrt{ }$ \\
\hline $\mathrm{U}-\mathrm{C}-\mathrm{O}$ & 150 & - & - & - & - & - \\
\hline $\mathrm{P}-\mathrm{C}-\mathrm{O}$ & 150 & - & - & - & $\sqrt{ }$ & - \\
\hline U-C-WR & 150 & - & - & - & - & $\sqrt{ }$ \\
\hline P-C-WR & 150 & - & - & - & $\sqrt{ }$ & $\sqrt{ }$ \\
\hline P-M-O & - & 100 & 150 & 76 & $\sqrt{ }$ & - \\
\hline P-M-WR & - & 100 & 150 & 76 & $\sqrt{ }$ & $\sqrt{ }$ \\
\hline
\end{tabular}

*(d): Diameter of cylindrical cross-section; **(a): Side of the square cross-section.

CFRP. Hence, the specimens are strengthened with CFRP wrapping (WR), and others are presented without strengthening $(\mathrm{O})$. The details of tested specimens are shown in Table 1 .

\subsection{Material properties}

Two types of concrete, i.e., regular concrete and expansive cement concrete, were used for the specimens. Regular concrete was used to build the original rectangular cube and circular specimens, and the expansive cement concrete was used to perform shape modification. Shape modification of a square section into a circular section resulted in an increase in the cross-sectional area equal to 1.76 times the original area.

For concrete mix design, $815 \mathrm{~kg}$ sand, $1100 \mathrm{~kg}$ gravel (the maximum size of $9.5 \mathrm{~mm}$ ), $400 \mathrm{~kg}$ Portland cement type II, and $200 \mathrm{~kg}$ water were used. The 28-day compressive strength of the concrete for the standard cylindrical specimens $(150 \times 300 \mathrm{~mm})$ was $30 \mathrm{MPa}$. In order to make the expansive concrete, expander material equivalent to one percent of cement weight was added to the concrete mix design. The 28-day compressive strength of the expansive concrete for the standard cylindrical samples $(150 \times 300 \mathrm{~mm})$ was measured as 35MPa. Unidirectional Carbon FiberReinforced Polymer (CFRP) was used to wrap specimens. The properties of the CFRP used as per the manufactures data are given in Table 2.

\subsection{Heating of specimens}

Specimens were heated about four months after the construction. An electric furnace with dimensions of $500 \mathrm{~mm} \times 500 \mathrm{~mm} \times 500 \mathrm{~mm}$ was used to heat the specimens. The method for placing specimens inside the furnace and the heating regimes are presented in Figures 1 and 2, respectively. To dry the specimens

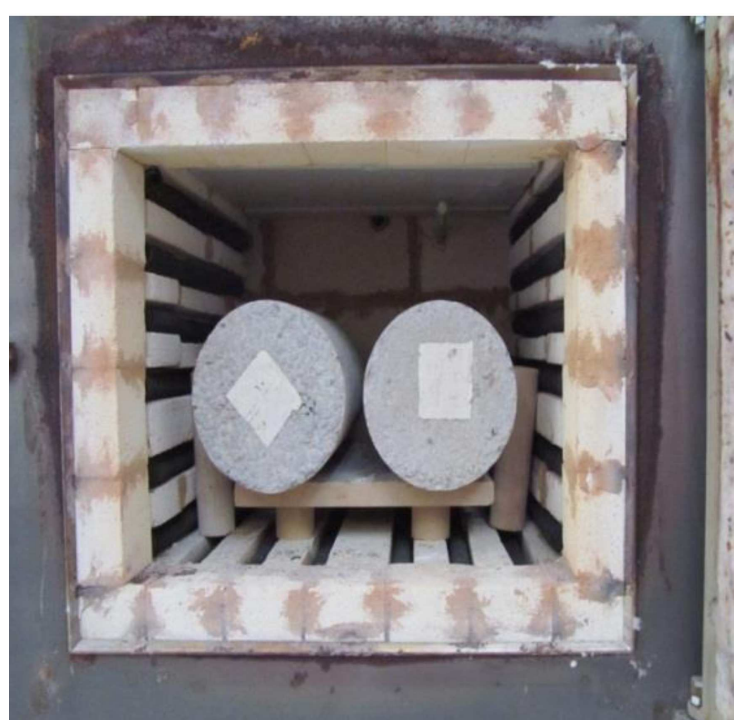

Figure 1. Furnace with concrete cylinders ready for heating.

Table 2. Carbon fiber-reinforced polymer characteristics.

\begin{tabular}{cccccc}
\hline $\begin{array}{c}\text { Product } \\
\text { name }\end{array}$ & $\begin{array}{c}\text { Thickness } \\
(\mathbf{m m})\end{array}$ & $\begin{array}{c}\text { Tensile } \\
\text { strength } \\
(\mathbf{M P a})\end{array}$ & $\begin{array}{c}\text { Modulus of } \\
\text { elasticity } \\
(\mathbf{G P a})\end{array}$ & $\begin{array}{c}\text { Elongation } \\
\text { at break }\end{array}$ & $\begin{array}{c}\text { Weight per } \\
\text { unit area } \\
\left(\mathbf{g r} / \mathbf{m}^{\mathbf{2}}\right)\end{array}$ \\
\hline Quantom wrap 200c & 0.111 & 4950 & 240 & $1.5 \%$ & 200 \\
\hline
\end{tabular}




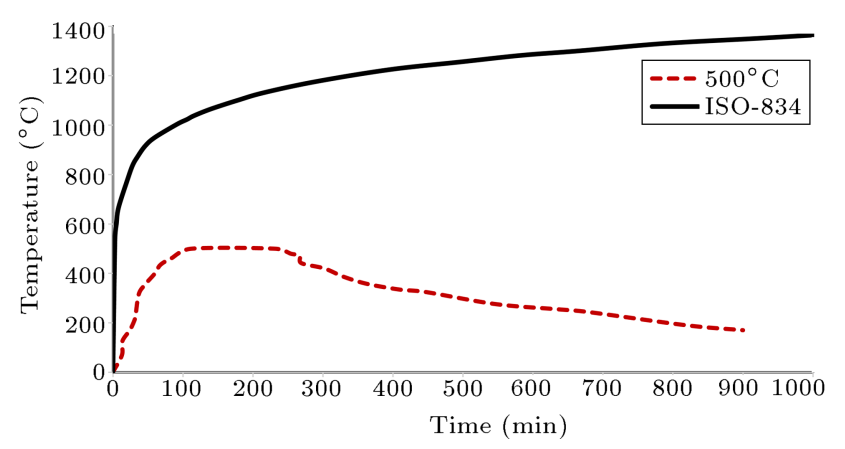

Figure 2. Time-temperature curves used in this study.

completely, they were placed inside an electric furnace for the duration of 24 hours at a temperature of $100^{\circ} \mathrm{C}$. In previous researches, for high temperatures, heating rate of $1-10^{\circ} \mathrm{C} / \mathrm{min}$ was used [43-45]. Average rate of heating was $250^{\circ} \mathrm{C} / \mathrm{h}$. However, it should be noted that the rate of heating used is considerably lower than ISO-834 regulation, which is presented in Figure 2. However, considering the capability of the furnace, the heating regime given in Figure 2, which has also been used by previous researchers, was utilized. Once the average temperature of the furnace reached $500^{\circ} \mathrm{C}$, the temperature was kept constant for two hours. Then, the furnace was turned off and the specimens were allowed to cool naturally in the furnace for 24 hours. Afterwards, the specimens were removed from the furnace and maintained under laboratory conditions until the time of testing.

\subsection{Repair process of heat damaged specimens} Since the specimens, exposed to fire, received no severe damage and only small cracks were observed on their surface, there is no need to take action to repair concrete surface before shape modification and performing CFRP wrap.

To modify the shape of specimens in the annular gap between cylindrical frameworks $(150 \times 300 \mathrm{~mm})$ and prismatic specimens, expansive concrete was used. Before placing concrete in the corners of the crosssection, a $10 \mathrm{~mm}$ chamfer was created to make the aggregates move in the concrete easily (Figure 3 ). It is noteworthy that before implementing the expansive concrete, the surfaces of the specimen were prepared based on BSEN1504 standard [46]. The loose concrete was removed using a steel wire brush, and the concrete substrate was prepared to make a better connection between regular and expansive concretes.

In addition, the specimens were placed in water before using the expansive concrete, since this would prevent regular concrete from absorbing the water of the expansive concrete.

The specimens were kept in steel formworks for four weeks after using the expansive concrete. Moreover, the top surface of concrete was regularly moistened using wet clothes. This curing method

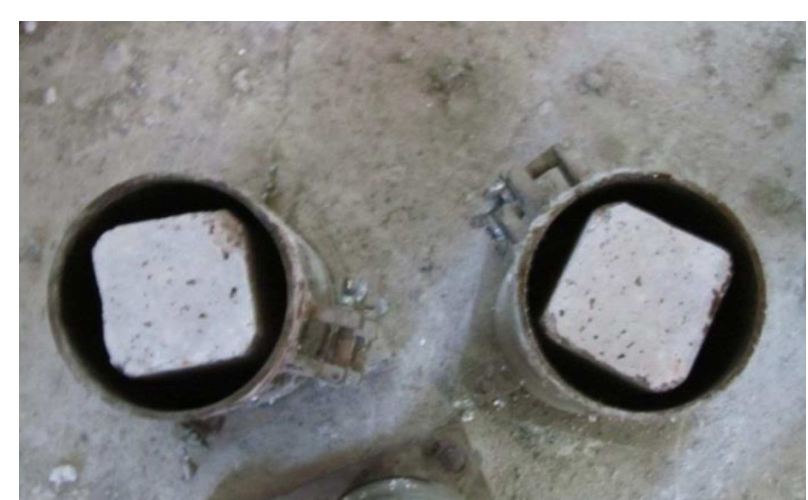

Figure 3. Shape-modification of square samples by using circular molds.

causes an increase in the volume of the expansive concrete. However, the formwork did not allow the volume of the concrete to increase. Therefore, this could create compressive stress between regular and expansive concretes, leading to a better connection between both types of concrete.

Wet lay-up technique was used for wrapping up the specimens. Before the use of CFRP, the surface of specimens was prepared based on BSEN1504 standard. The epoxy resin called Sikador330 was used before the CFRP wrapping around the concrete.

A thin layer of epoxy was applied on the surfaces of the specimen to fill all the voids, cavities, and micro cracks. Then, an initial layer of CFRP was used along fibers for wrapping. The trapped air bubble was removed using roller and hand pressure. This was repeated constantly until reaching full impregnation of composite fibers with adhesive.

It should be noted that the mentioned procedure was replicated for the second layer of CFRP. To have a better connection, $100 \mathrm{~mm}$ fiber along the longitudinal direction was used for overlapping; then, a thin layer of epoxy was applied on the fibers to fully saturate them. The time required for the curing of epoxy is 72 hours in the laboratory environment.

\subsection{Test setup and testing procedure}

Before testing, all specimens were capped to achieve parallel surfaces and, hence, uniform load distribution. In order to measure strain, Linear Variable Displacement Transducers (LVDTs) were used. As shown in Figure 4, two LVDTs were installed during loading time. The specimens were tested under axial pressure up to failure by a machine that has a capacity of $2000 \mathrm{kN}$, and the data were monitored and logged by data logger. The strain measurement method for square and circular specimens is presented in Figure 4.

\section{Experimental results and discussion}

\subsection{Test observation and failure mode}

All of the concrete specimens were subjected to uniaxial 


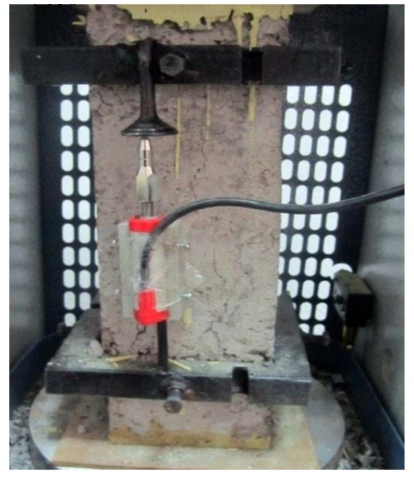

(a)

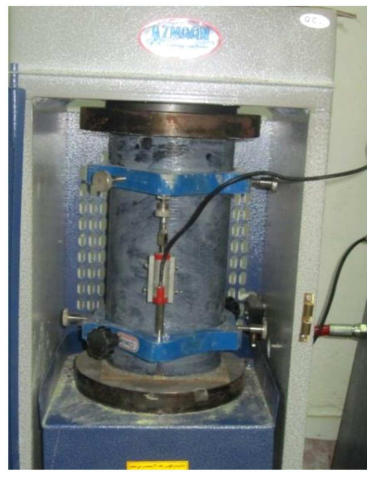

(b)
Figure 4. Strain measurement for (a) square and (b) circular specimens.

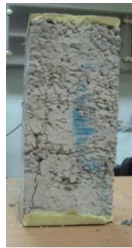

$\mathrm{U}-\mathrm{S}-\mathrm{O}$

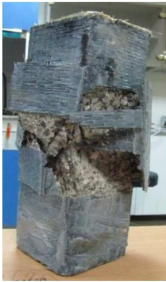

$\mathrm{U}-\mathrm{S}-\mathrm{WR}$

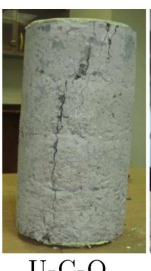

$\mathrm{U}-\mathrm{C}-\mathrm{O}$

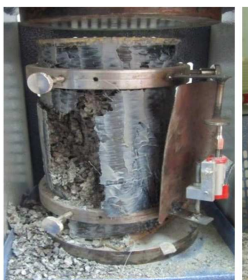

U-C-WR

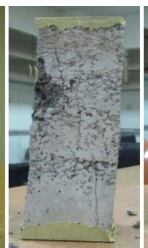

$\mathrm{P}-\mathrm{S}-\mathrm{O}$

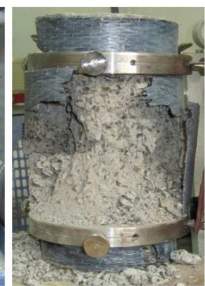

P-C-WR

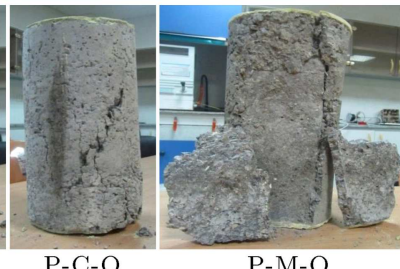

$\mathrm{P}-\mathrm{M}-\mathrm{O}$

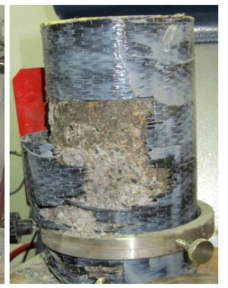

P-M-WR
Figure 5. Failed square and circular, unheated and post-heated specimens with and without shape modification.

compression load until failure. Images of specimens after uniaxial compression test are shown in Figure 5. The U-S-O specimens and the square specimens without strengthening and heating had concrete crushing type of specimen failure. Failure of P-S-O specimens was similar to that of U-S-O specimens, except that more cracks or collapse was observed in the P-S-O specimens. On the other hand, for U-S-WR and P-S-WR specimens, failure resulted from concrete crushing, which was followed by fracture of CFRP composite jackets at the corners. Brittle fracture occurs due to stress concentration near the section corners and the lack of confinement on the flat sides, which eliminated membrane action. Failure of U-C-O specimens occurred due to the combination of column and shear failure, whereas the $\mathrm{P}-\mathrm{C}-\mathrm{O}$ specimens had wedge failure. The failures of U-C-WR and P-C-WR specimens occurred suddenly and explosively with a high-pitched noise as a result of a rupture in the CFRP composites. The strengthened circular specimens' failure was detected in the middle of its height. The rupture mode in the CFRP layers of these specimens represents the accumulation of a large amount of strain energy created as a result of confinement. When failure of shape-modified specimens without CFRP wrapping (P-M-O) is considered, the layer of expansive concrete gets separated from the main concrete due to low bond. Hence, after the failure, the main concrete was found without fracture. For shape-modified specimens with CFRP wrapping, such as C-WR specimens, the failure occurred suddenly and explosively with a loud booming noise due to rupture at the mid-height of the specimen. However, the separation between the central core and the expansive concrete was also observed in these specimens.

\subsection{The stress-strain behavior of specimens subjected to compression}

Axial strain was measured by using two LVDTs. The axial stress was calculated by using the axial compressive load divided by the specimen's cross-sectional area. Figure 6 shows the axial stress versus axial strain response of all specimens with square cross-section including the reference specimens of U-S-O, reference specimens with wrapping U-S-WR, and the specimens with square cross-section exposed to heating, P-S-O, and U-S-WR. By comparing the stress-strain diagrams related to the un-heated specimens, it is observed that the CFRP wrapping has no significant influence on the initial slope, while it has considerable effect on the strength and ultimate strain of the specimens, which can be due to the confinement of the CFRP composite sheets to prevent failures of specimens and to resist high strain. On the other hand, the specimens exposed to heating undergo significant loss of stiffness and strength, while the maximum strain of these specimens increases. The reduction in stiffness could be a result of small cracks and the pores created in concrete owing to the water evaporation during heating. As shown in Figure 6, once the specimens strengthened with CFRP composite sheets were subjected to heating, the stiffness and strength of the specimens increased.

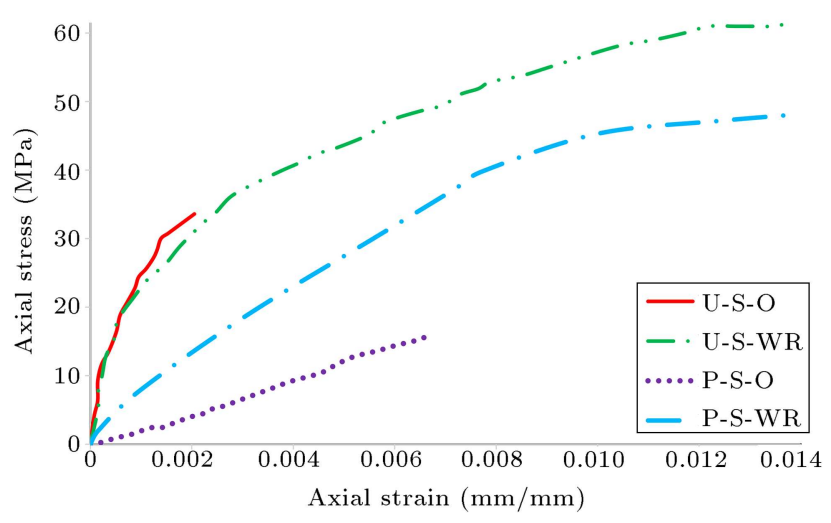

Figure 6. Axial stress-strain behavior of specimens with square cross-section. 
However, this growth is not enough for the specimens to reach the stiffness of the baseline specimens. In addition, an increase in strength was almost $56 \%$ more than that of the reference specimens and $20 \%$ less than that of U-S-WR specimens. This reduction occurred due to the presence of cracks, leading to a loss of strength in the core of heated concrete.

Figure 7 presents axial stress versus axial strain of the specimens with circular a cross-section, including U-C-O, P-C-O, U-C-WR, and P-C-WR specimens, as compared with reference specimens (U-S-O). Based on our study of the diagrams related to specimens exposed to heating, as expected, the stiffness and the strength significantly dropped. However, after strengthening with CFRP composite wrapping, the stiffness improved. However, it should be noted that the increased stiffness is not as high as the initial stiffness. The strength of the specimens considerably improved after strengthening with CFRP, which is due to the confinement effect that prevented the destruction of the central core.

Figure 8 shows the axial stress-strain curves of P-M-O, P-M-WR, U-S-O, U-C-O, P-S-O, and P-C-O specimens. The curves of U-S-O, U-C-O, P-S-O, and P$\mathrm{C}-\mathrm{O}$ specimens were included for comparison purposes.

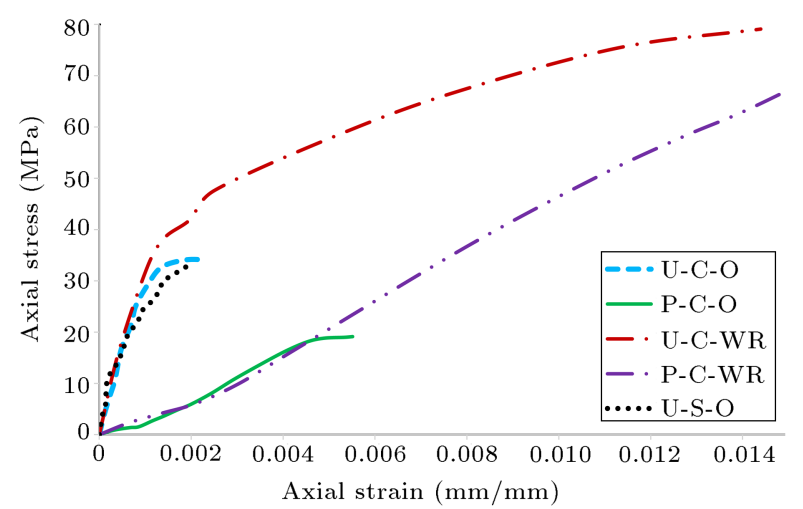

Figure 7. Axial stress-strain behavior of specimens with circular cross-section.

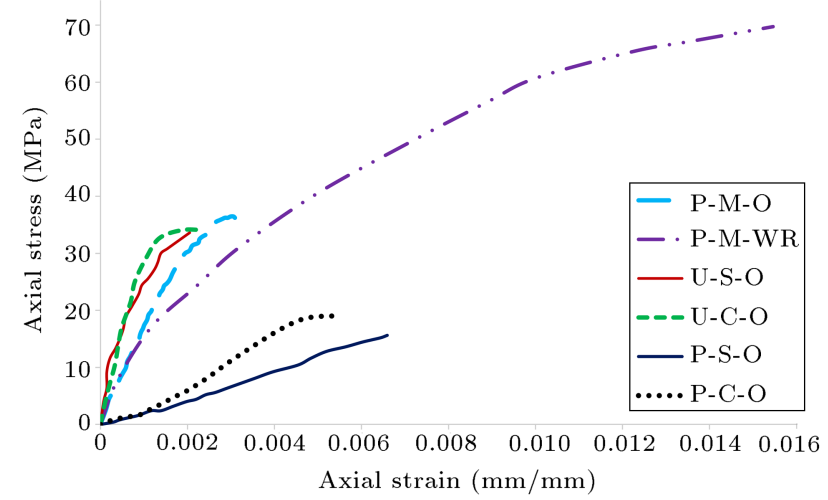

Figure 8. Comparison of axial stress-strain behavior between modified and unmodified specimens.
Based on Figures 6 to 8, the stiffness of specimens increased with the application of shape modification. Moreover, the strength of shape-modified and wrapped specimens considerably improved, whilst the strength of unwrapped specimens was close to that of original specimens.

It is noteworthy that shape modification for the damaged specimens could largely compensate the stiffness reduction, and the use of CFRP wrapping could considerably improve the compressive strength. However, this was not enough to compensate the stiffness and the strength to return to their initial values.

\subsection{Compressive strength}

The results of compressive strength for the studied specimens are given in Figure 9. Compressive strength of the reference specimens was $33.4 \mathrm{MPa}$. When the specimens were heated, the square and circular specimens had $56 \%$ and $42 \%$ drop in their compressive strength, respectively. This reduction in strength is attributed to the dehydration of CSH gel as well as to the volumetric expansion resulting from the transformation of the chemical compounds $\mathrm{Ca}(\mathrm{oh})_{2}$ to $\mathrm{CaO}$. Strengthening by CFRP wrapping of the unheated specimens caused $98.7 \%$ and $122 \%$ increases in the compressive strength of the square and circular specimens, respectively. However, an increase in compressive strength was more remarkable for circular specimens. In addition, strengthening by CFRP composite for specimens subjected to heating led to a prominent increase in their compressive strength, which was three times higher than that of the P-O specimen. By studying the compressive strength of the square and circular specimens, it is observed that the drop in strength resulting from heating is less for $\mathrm{C}$ specimens, and also the growth of strength in these series of specimens caused by strengthening with CFRP is more than that in square specimens. According to the compressive strength of shape-modified specimens, it can be concluded that shape modification and repair-

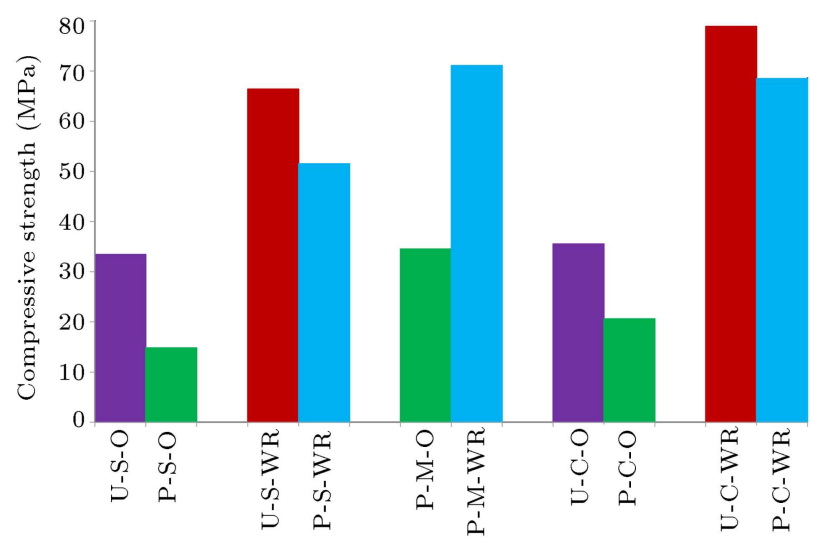

Figure 9. Compressive strength of the studied specimen. 
ing of fire-damaged specimens led to an increase in the compressive strength. This growth was to the extent that, for the specimens without wrapping, the compressive strength of shape-modified specimens reached the compressive strength of unheated specimens. Once CFRP sheets wrapped the shape-modified specimens, their compressive strength showed an increase, which was two times higher than those of P-M-O specimens and four times higher than those of $\mathrm{P}-\mathrm{S}-\mathrm{O}$ specimens. This amount is more than that of U-S-WR and P-SWR specimens, while it is less than the compressive strength of U-C-WR specimens. This increase in strength occurs due to both the strength created by expansive concrete and the shape modification of crosssections into circular section. Therefore, uniform stress was exerted on CFRP sheets, and the confinement effect improved.

\subsection{Elastic modulus}

Figure 10 is presented to provide further examination of the effect of cross-section shape modification and also the effect of strengthening with CFRP on the elastic range of loading of the concrete.

The primary parts of stress-strain curves are linear (Figure 10). The origin point has been linearly connected to a point of stress-strain curve, corresponding to $40 \%$ of maximum stress in reference specimen (US-O). It can clearly be concluded (Figure 10) that the influence of shape modification and strengthening with CFRP is obvious on the primary slope and stiffness of stress-strain curve for the studied specimens. The slopes of curves for U-S-O, U-S-WR, U-C-O, and U$\mathrm{C}$-WR specimens are almost identical so that the mentioned curves can overlap (Figure 10).

The compliance of the four mentioned lines shows that the confinement with CFRP has little impact on the stiffness and primary slope (elastic range) of stressstrain curve. In other words, the effect of strengthening with CFRP in the elastic state of loading is negligible. It is observed that the slope of curves has significantly dropped after exposure to heating. This issue is clearly visible in $\mathrm{P}-\mathrm{S}-\mathrm{O}$ and $\mathrm{P}-\mathrm{C}-\mathrm{O}$ specimens; however,

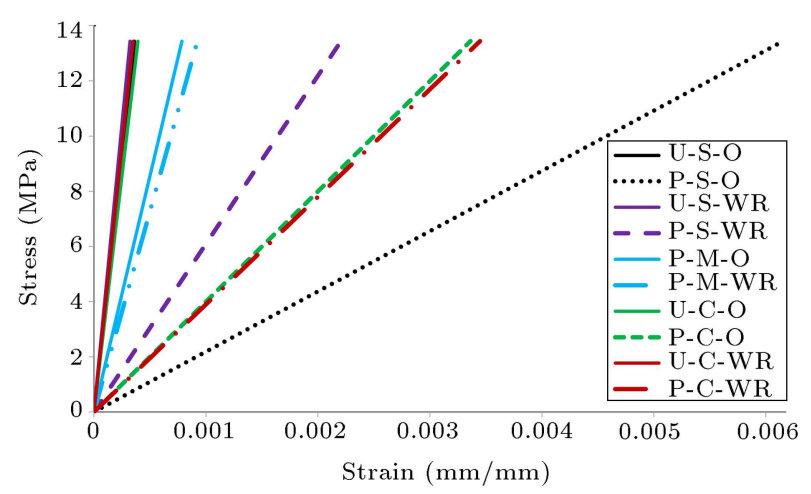

Figure 10. Comparison of stress-strain behavior among specimens in elastic range. the drop in $\mathrm{P}-\mathrm{S}-\mathrm{O}$ specimen is more that in $\mathrm{P}-\mathrm{C}-\mathrm{O}$ specimen.

The slope and primary stiffness of specimens has greatly increased owing to the shape modification of cross-sections. However, this growth has not been enough to reach the initial slope before heating. It is observed that the shape modification can considerably enhance the slope and primary stiffness of stress-strain curve or the stiffness of concrete in the elastic state. Figure 11 demonstrates the effects of heating, shape modification, and strengthening with CFRP wrapping on elastic modulus of concrete specimens. In this study, in order to examine the effect of fire on the elastic modulus of concrete in the elastic range and also to investigate the proposed strengthening method for restoring the reduction in stiffness, elastic modulus has been used.

Elastic modulus is defined as a linear slope corresponding to $40 \%$ of maximum stress in original specimens (U-S-O); for P-S-O and P-C-O specimens, the linear slope is calculated according to $40 \%$ of maximum stress in these specimens.

The average amount of elastic modulus related to the three studied specimens is shown in Figure 11. This figure shows that the modulus of elasticity has sharply fallen due to heating effect. This reduction occurs due to the creation of micro-cracks and softening of the concrete after heating and reduction in bonds. Moreover, an increase in porosity due to evaporation of the concrete water is another factor for the reduction. The modulus of elasticity can be improved by strengthening with two layers of CFRP.

The modulus of elasticity for U-S-O specimen is $37.1 \mathrm{GPa}$ that has declined to $2.1 \mathrm{GPa}$ in $\mathrm{P}-\mathrm{S}-\mathrm{O}$ specimen due to heating. Thanks to shape modification, the modulus of elasticity for P-S-O specimens has increased by more than eight times and reached 17.1 GPa, showing the effect of shape modification on elastic modulus or the stiffness of elastic range for heated concrete. However, the effect of confinement on modulus of elasticity of concrete is not perceptible.

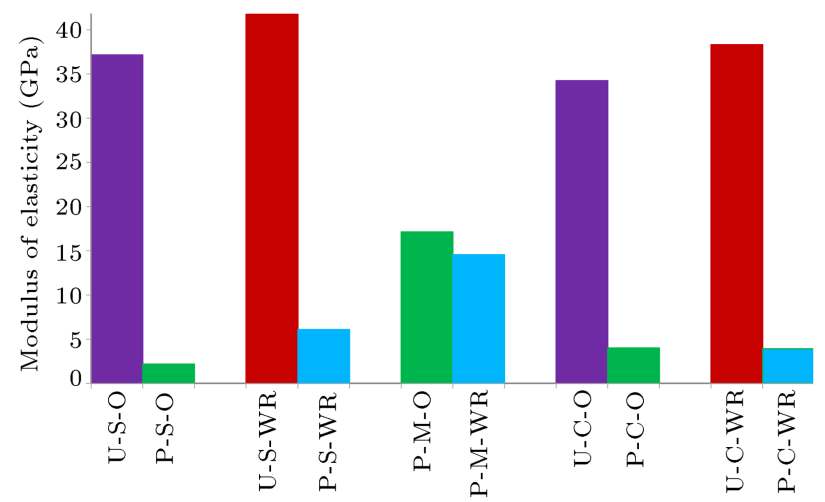

Figure 11. Average modulus of elastic for the studied specimens. 
According to Figure 11, the numerical value of elastic modulus for unheated specimens U-S-O, U-S-WR, U$\mathrm{C}-\mathrm{O}$, and $\mathrm{U}-\mathrm{C}-\mathrm{WR}$ ranges from 34 to $41 \mathrm{GPa}$. Once the specimens are exposed to $500^{\circ} \mathrm{C}$ temperature, elastic modulus sharply reaches and declines to 2 to $4 \mathrm{GPa}$ range. Confinement with CFRP had minor effect on modulus of elasticity, although the confinement significantly increased the compressive strength of concrete.

Figure 11 shows that shape modification from square to circular one in heated specimens causes a significant growth in elastic modulus or, in other words, the stiffness of elastic range. It is worth noting that the effect of CFRP wrapping on the overall stiffness was negligible for heated specimens, which may be a result of insignificant effect of confinement in the elastic range of loading. The confinement of CFRP layers is activated when the concrete reaches the nonlinear state; by applying continuous pressure on the concrete core, it will continue until reaching the failure of CFRP jacket. Therefore, the behavior of elastic state of the wrapped heated specimens with CFRP is similar to that of the heated specimens without wrapping.

The central core of shape-modified specimens was made of fire-damaged concrete; however, the external cover of the specimens consisted of expansive concrete, which has high stiffness. An increase in modulus of elasticity in shape-modified specimens can be due to the use of expansive concrete. Therefore, for firedamaged concrete, it is possible to compensate the drop in elastic modulus or stiffness in an elastic range by using expansive concrete as external cover.

\section{Conclusion}

This study examined the effect of repairing and shape modification of fire-damaged specimens using expansive concrete and strengthening with CFRP. The performance of shape-modified post-heated specimens subjected to axial compression and the effect of CFRP wrapping on the performance of specimens were investigated and compared with the un-heated specimens considered as reference specimens. Based on the experimental studies, the following concluding remarks are presented:

1. Failure of specimens without wrapping occurred due to concrete crushing, while, in the wrapped specimens, the failure occurred due to concrete crushing, followed by rupture of CFRP composite with explosion and a loud booming noise. Failure in shape-modified specimens without wrapping occurred in the form of separation of the two concrete layers from each other, whereas failure in shapemodified specimens with wrapping was similar to that in the wrapped circular specimens;

2. The compressive strength of the concrete spec- imens, exposed to $500^{\circ} \mathrm{C}$ heat, significantly decreased. The reduction for $\mathrm{S}$ series specimens and C series specimens were, respectively, $56 \%$ and $42 \%$ relative to un-heated specimens;

3. The compressive strength of the specimens after strengthening with two layers of CFRP wrapping significantly increased. An increase in the unheated specimens was more than twice; for firedamaged specimens, it was significant and reached more than three times the growth for the P-O specimens;

4. Shape modification and repairing of the firedamaged specimens caused an increase in compressive strength and reached the strength of square specimens in unwrapped specimens. When they were strengthened, the strength improved more than two times that of unwrapped specimens and more than four times that of heated square specimens;

5. The initial slopes of the curve corresponding to the unheated specimens and also to the unheated confined specimens were nearly identical and consistent with each other. However, by placing the specimens exposed to the heat, the slope in the elastic state of specimens sharply decreased; confinement also has little effect on the initial stiffness. Therefore, the slope of stress-strain curve in the elastic range could considerably increase and largely compensate for fire-damaged specimens using shape modification;

6. The modulus of elasticity sharply decreased due to heating. The reduction in modulus of elasticity of fire-damaged specimens was more than that in compressive strength of specimens;

7. The effect of CFRP wrappings on the modulus of elasticity was negligible because of insignificant effect of concrete confinement in the elastic state of loading. However, modifying the square section shape into a circular one had considerable effect on the modulus of elasticity of fire-damaged specimens so that, with shape modification, the reduction in this parameter was compensated for an increase more than 8 times with respect to the damaged specimens while not obtaining the initial value.

\section{References}

1. Yaqub, M. and Bailey, C.G. "Repair of fire damaged circular reinforced concrete columns with CFRP composites", Construction and Building Materials, 25, pp. 359-370 (2011).

2. Concrete Society Assessment "Design and repair of fire-damaged concrete structures", Technical Report, 68, Camberley, Surrey, UK (2008).

3. Bastami, M., Chaboki-Khiabani, A., Baghbadrani, M., and Kordi, M. "Performance of high strength concretes 
at elevated temperatures", Scientia Iranica, 18(5), pp. 1028-1036 (2011).

4. Mehta, P.K. and Monteiro, P.J.M., Concrete: Microstructure, Properties, and Materials, McGraw-Hill, New York, NY, USA (2006).

5. Chen, G.M., He, Y.H., Yang, H., Chen, J.F., and Guo, Y.C. "Compressive behavior of steel fiber reinforced recycled aggregate concrete after exposure to elevated temperatures", Construction and Building Materials, 71, pp. 1-15 (2014).

6. Gupta, T., Siddique, S., Sharma, R.K., and Chaudhary, S. "Effect of elevated temperature and cooling regimes on mechanical and durability properties of concrete containing waste rubber fiber", Construction and Building Materials, 137, pp. 35-45 (2017).

7. Huang, Z., Liew, J.Y.R., and Li, W. "Evaluation of compressive behavior of ultra-lightweight cement composite after elevated temperature exposure", Construction and Building Materials, 148, pp. 579-589 (2017).

8. Baradaran-Nasiri, A. and Nematzadeh, M. "The effect of elevated temperatures on the mechanical properties of concrete with fine recycled refractory brick aggregate and aluminate cement", Construction and Building Materials, 147, pp. 865-875 (2017).

9. Xiong, M.X. and Liew, J.Y.R. "Mechanical behaviour of ultra-high strength concrete at elevated temperatures and fire resistance of ultra-high strength concrete filled steel tubes", Materials and Design, 104, pp. 414427 (2016).

10. Li, L., Jia, P., Dong, J., Shi, L., Zhang, G., and Wang, Q. "Effects of cement dosage and cooling regimes on the compressive strength of concrete after postfire-curing from $800^{\circ} \mathrm{C}$ ", Construction and Building Materials, 142, pp. 208-220 (2017).

11. Xiao, J., Li, Zh., Xie, Q., and Shen, L. "Effect of strain rate on compressive behaviour of high-strength concrete after exposure to elevated temperatures", Fire Safety Journal, 83, pp. 25-37 (2016).

12. Choi, E., Kim, Y.W., Chung, Y.S., and Yang, K.T. "Bond strength of concrete confined by SMA wire jackets", Phys Proc, 10, pp. 210-215 (2010).

13. Choi, E., Chung, Y.S., Kim, Y.W., Kim, J.W. "Monotonic and cyclic bond behavior of confined concrete using NiTiNb SMA Wires", Smart Mater Struct, 20(7), pp. 1-11 (2011).

14. Calderón, P.A., Adam, J.M., Ivorra, S., Pallarés, S.F., and Giménez, E. "Design strength of axially loaded RC columns strengthened by steel caging", Materials \& Design, 30(10), pp. 4069-4080 (2009).

15. Turgay, T., Polat, Z., Koksal, H.O., Doran, B., and Karakoç, C. "Compressive behavior of largescale square reinforced concrete columns confined with carbon fiber reinforced polymer jackets", Materials \& Design, 31(1), pp. 357-364 (2010).

16. Bisby, L.A., Green, M.F., and Kodur, V.K.R. "Fire endurance of fiber-reinforced polymerconfined concrete columns", ACI Struct. J., 102(6), pp. 883-891 (2005).
17. Chowdhury, E.U., Bisby, L.A., Green, M.F., and Kodur, V.K.R. "Investigation of insulated CFRP wrapped reinforced concrete columns in fire", Fire Safety J., 42(6), pp. 452-460 (2007).

18. Maghsoudi, A.A. and Akbarzadeh Bengar, H. "Acceptable lower bound of the ductility index and serviceability state of $\mathrm{RC}$ continuous beams strengthened with CFRP sheets", Scientia Iranica, 18(1), pp. 36-44 (2011).

19. Ghasemi, S., Maghsoudi, A.A., Akbarzadeh Bengar, H., and Ronagh, H.R. "Sagging and hogging strengthening of continuous unbonded posttensioned HSC beams by NSM and EBR", J. Compos. Constr, 20(2), pp. 1-13 (2016).

20. Balaguru, P., Nanni, A., and Giancaspro, J., CFRP Composites for Reinforced and Prestressed Concrete Structures, Taylor and Francis, New York (2009).

21. Yan, Z. "Shape modification of rectangular columns confined with CFRP composites", PhD Thesis, Salt Lake City (UT), Dept. Civil and Environmental Eng., University of Utah (2005).

22. Behzard, P., Sharbatdar, M.K., and Kheyroddin, A. "Different NSM CFRP technique for strengthening of RC two-way slabs with low clear cover thickness", Scientia Iranica, 23(2), pp. 520-534 (2016).

23. Shin, J., Scott, D.W., Stewart, L.K., Yang, Ch., Wright, T.R., and Roches, R.D. "Dynamic response of a full-scale reinforced concrete building frame retrofitted with CFRP column jackets", Engineering Structures, 125, pp. 244-253 (2016).

24. Hadi, M.N.S. "Behaviour of eccentric loading of CFRP confined fibre steel reinforced concrete columns", Constr Build Mater, 23(2), pp. 1102-1108 (2009).

25. Parvin, A., Altay, S., Yalcin, C., and Kaya, O. "CFRP rehabilitation of concrete frame joints with inadequate shear and anchorage details", J. Compos Constr, 14(1), pp. 72-82 (2010).

26. Teng, J.G., Chen, J.F., Smith, S.T., and Lam, L., CFRP Strengthened RC Structures, Wiley Chichester (2002).

27. Debaiky, S.A. Green, M.F., and Hope, B.B. "Carbon fibre-reinforced polymer wraps for corrosion control and rehabilitation of reinforced concrete columns", ACI Mater J., 99(2), pp. 129-137 (2002).

28. Ilia, E., Mostofinejad, D., and Moghaddas, A. "Performance of corner strips in CFRP confinement of rectilinear RC columns", Scientia Iranica, 22(6), pp. 2024-2032 (2015).

29. Issa, M.A., and Rajai, Z.A. "Experimental and parametric study of circular short columns confined with CFRP composites", J. Compos Constr, 13(2), pp. 135147 (2009).

30. Maaddawy, T. "Post-repair performance of eccentrically loaded RC columns wrapped with CFRP composites", Cement Concr Compos, 30(9), pp. 822-830 (2008). 
31. Toutanji, H., Han, M., Gilbert, J., and Matthys, S. "Behaviour of large scale rectangular columns confined with CFRP composites", J. Compos Constr, (ASCE), 29, pp. 62-71 (2009).

32. Chowdhury, E.U., Bisby, L.A., Green, M.F., and Kodur, V.K.R. "Residual behaviour of fire exposed reinforced concrete beams prestrengthened in flexure with fibre reinforced polymer sheets", J. Compos Constr, 12(1), pp. 44-52 (2008).

33. Haddad, R.H., Shannag, M.J., and Hamad, R.J. "Repair of heat damaged reinforced concrete T-beams using FRC jackets", J. Mag. Concr. Res., 59(3), pp. 223-231 (2007).

34. Yan, Z. and Zhisheng, X.U., Experimental Study on Safety Test for Reinforced Concrete Columns Strengthened with Carbon Fibre Reinforced Polymers After Fire, Disaster Prevention Science and Safety Technology Institute, Central South University, Changsha, China (2005).

35. Zhong, T. and Lin-Hai, H. "Behaviour of fire-exposed concrete-filled steel tubular beam columns repaired with CFRP wraps", J. Thin-walled Struct, 45(1), pp. 63-76 (2007).

36. Zhong, T., Lin-Hai, H., and Ling-Ling, W. "Compressive and flexural behavior of CFRP-repaired concretefilled steel tubes after exposure to fire", J. Constr Steel Res, 63(8), pp. 1116-1126 (2007).

37. Karbhari, V.M. and Gao, Y. "Composite jacketed concrete under uniaxial compression verification of simple design equations", J. Mater Civil Eng., ASCE, 9(4), pp. 185-193 (1997).

38. Rochette, P. and Labossiére, P. "Axial testing of rectangular column models confined with composites", J. Compos Constr ASCE, 4(3), pp. 129-136 (2000).

39. Maaddawy, T.E., Sayed, M.E., and Abdel-Magid, B. "The effects of cross-sectional shape and loading condition on performance of reinforced concrete members confined with carbon fiber-reinforced polymers", Materials \& Design, 31, pp. 2330-2341 (2010).

40. Yan, Z. and Pantelides, C.P. "Concrete column shape modification with FRP shells and expansive cement concrete", Construction and Building Materials, 25, pp. 396-405 (2011).

41. Ma, Ch., Apandi, N., Yung, S., Hau, Ng., Haur, L., Awang, A., and Omar, W. "Repair and rehabilitation of concrete structures using confinement: A review", Construction and Building Materials, 133, pp. 502-515 (2017).

42. Shin, J., Scott, D.W., Stewart, L.K., Yang, C.S., and DesRoches, R. "Dynamic response of a full-scale reinforced concrete building frame retrofitted with FRP column jackets", Engineering Structures, 125, pp. 244-253 (2016).

43. Molhotra, H.L. "The effect of temperature on the compressive strength of concrete", Mag. Concr. Res, 8(22), pp. 85-94 (1956).

44. Wu, B., Ma, Z.C., and Ou, J.P. "Experimental research on deformation and constitutive relationship of concrete under axial loading and high temperature", $J$. Build. Struct, 20(5), pp. 42-49 (1999).

45. Chang, Y.F., Chen, Y.H., Sheu, M.S., and Yao, G.C. "Residual stress strain relationship for concrete after exposure to high temperatures", Cement and Concrete Research, 36, pp. 1999-2005 (2006).

46. The Concrete Society, "Repair of concrete structures with reference to BS EN 1504", Technical Report No. 69 (2009).

\section{Biographies}

Mehdi Hosseinpour is a PhD Candidate at the Civil Engineering Department at Eastern Mediterranean University (EMU) studying Structural Engineering branch. His research interests include the use of FRP in reinforced concrete structures.

Murude Celikag is an Associate Professor at the Department of Civil Engineering at Eastern Mediterranean University (EMU). She received her Master and PhD degrees from University of Sheffield, UK in 1986 and 1990, respectively. Her research interests include the ductility of steel beam to column connections, seismic performance evaluation of mixed framed structures, performance of special truss moment frames, optimization of steel truss systems, and progressive collapse analysis of structures.

Habib Akbarzadeh Bengar is an Associate Professor at the Department of Civil Engineering at the University of Mazandaran. He received his Master and $\mathrm{PhD}$ degrees from University of Kerman, Iran in 2004 and 2010, respectively. His research interests include the strengthening of reinforced concrete structures with FRP, flexural behavior of high strength concrete members, behavior of fiber reinforced concrete member in flexure and compression, seismic behavior and design of reinforced concrete frame, and shear wall system and behavior of concrete structures under fire. 